\title{
Temporal Analysis of Sweet Chestnut Decline in Northeastern Portugal Using Geostatistical Tools
}

\author{
J. Castro ${ }^{1}$, J.C. Azevedo ${ }^{1}$ and L. Martins ${ }^{2}$ \\ ${ }^{1}$ Instituto Politécnico de Bragança \& CIMO - Centro de Investigação de Montanha, \\ 5301-855, Bragança, Portugal \\ 2 Universidade de Trás-os-Montes e Alto Douro, 5000-911 Vila Real, Portugal
}

Keywords: aerial photography, Castanea sativa, kriging interpolation, Phytophthora cinnamomi, Cryphonectria parasitica, Portugal

\begin{abstract}
The rising demand for sweet chestnut (Castanea sativa) in Portugal and elsewhere in Europe has led to more intensive management practices to increase nut production. This intensification has potentially increased the widespread of ink and chestnut blight diseases, causing decline in sweet chestnut orchards health and production and limiting the establishment of new planted areas. In this study we estimated chestnut decline along the last twenty years (1986 to 2006) in the northern part of Portugal using 1986, 1995 and 2006 aerial photography to quantify the damage at the tree level within fixed sample plots according to a categorical scale. Mean damage and damage variance in each date, however, were not significantly different. Geostatistical analyses indicated, however, changes in the spatial distribution of damaged and undamaged areas over time. The spread of decline in the region of study was estimated using Kriging based on the spherical model. During the examined period we observed spread of chestnut decline and increasing damage levels in regions where damage is systematically high. The chestnut productive surface in the region has increased in the last twenty years because new plantations exceeded mortality areas. The spatial analyses applied here have made clearer the relations between the spread of chestnut decline and geographical variables.
\end{abstract}

\section{INTRODUCTION}

Chestnut ink disease caused by Phytophthora cinnamomi Rands is a major threat to the sustainability of chestnut agro-ecosystems in the northern part of Portugal where many stands contain clusters of dead and dying trees interspersed with healthy trees (Fonseca et al., 2004). As symptoms, trees exhibit root-rot, necrotic inner bark lesions in the collar region. In the summer, trees may die suddenly with brown leaves and burrs attached to their branches while others remain alive in a declining condition for several years. In northern Portugal, chestnut trees are grown in mountain areas from 600 to $1000 \mathrm{~m}$ a.s.l., with rye and potatoes as understorey crops. Soils are usually shallow with high acidity and low organic matter content, as well as low extractable phosphorus and exchangeable bases (Portela et al., 2003, 1999). Soil compaction and root damage from wheel traffic and equipment associated with tillage are common (Fonseca et al., 2004).

The increased demand for chestnut has been satisfied by expanding the area in production, increasing the use of nitrogen, and intensifying management practices such as manuring. New plantations have been used to reduce the negative socio-economic impacts of mortality caused by ink disease and also by chestnut blight (Cryphonectria parasitica (Murr.) Barr), a recent pathogen in the region. However, the large scale incidence of sweet chestnut diseases and the factors affecting their spread as well as the spatial and temporal dynamics of mortality and new plantations are not well understood.

Monitoring chestnut health requires expedite methods for damage evaluation because, under favorable conditions, diseases rapidly spread by zoospores and chlamydospores through water and movement of soil particles (Zentmyer, 1980). The control of ink disease is based on preventive measures that should be applied at a regional scale to be effective. As a consequence, an efficient monitoring system able to provide 
information on number and size of infected foci is necessary (Vannini et al., 2005).

Aerial photography has proven useful in detecting chestnut blight foci (Bissegger and Heiniger, 1994; Ambrosini et al.,1997; Martins et al., 2005, 2007, 2008) in Portugal.

Geostatistical methods, developed in the 1960s for mining and oil prospection (Krige, 1951), can be used to analyze and predict the spread of natural phenomena with spatial variability, like environmental sciences, ecology, forestry and also in plant pathology (e.g., Diggle, 2000). We used conventional aerial images and geostatistical methods to analyze the spatial distribution of chestnut disease affected areas over time and to monitor and evaluate chestnut decline since 1986.

\section{MATERIAL AND METHODS}

This study was conducted in the Padrela Mountain region (12,162 ha), Trás-osMontes region, Northeastern Portugal, where sweet chestnut is a crucial resource. It comprises the parishes of Carrazedo Montenegro, S. João Corveira, Padrela, Tazem, St Ribeira Alhariz, Serapicos and Curros.

We used aerial photography from 1995 (infrared false color) to exhaustively map sweet chestnut orchards in the study area. The accuracy assessment of the photointerpretation was made by Cohen's kappa index of agreement with ground truth data (Cohen, 1960; Congalton, 1991). Distribution of chestnut orchards in 1986 and 2006 was estimated based on sampling over the same area (see below) using a 1986 panchromatic aerial coverage and a 2006 true color composite. The coverage from 1986, the only not already orthorectified, was orthorectified with PCI - OrthoEngine software.

A random sampling scheme was defined in a GIS (ArcGis 9.2). Circular 20-m radius sampling plots $\left(1,256.6 \mathrm{~m}^{2}\right)$ were established in the corresponding locations. Within these plots we evaluated tree health condition visually on-screen based on a five level categorical scale ( 1 - healthy to 5 - decrepit) in each of the dates. This classification has been used before in this and other regions of Portugal and the ground truth tested by Martins et al. (2001, 2007). Within the same plots we evaluated also tree mortality and recruitment (new plantations).

We used variography to analyze the spatial dependence of disease incidence data of the health assessment process above. The semivariogram is a graphical representation of similarity (semi-variance) of data pairs, in this case the health condition of a pair of trees, as a function of the lag distance (h), i.e., the distance between each data pair. As paired data values become less similar, the semivariogram increases in value (Isaaks and Srivastava, 1989). The spatial dependence can be classified assuming the nugget as a percentage of the sill: $<25 \%$ (strong), between 25 and $75 \%$ (moderate), and $>75 \%$ (weak spatial dependence) (Cambardella et al., 1994). A mathematical function is empirically chosen to fit the semivariogram. The ordinary kriging leads to a prediction map of the tree health condition evaluation. The best fit should minimize the prediction errors, i.e., the difference between known (At) and interpolated locations (Ft), but also should make sense in terms of the natural process to be analyzed (Soares, 2000).

\section{RESULTS AND DISCUSSION}

Chestnut orchards in 1995 covered 2,234 ha (18.4\%) of the study area (Cohen's kappa index of agreement $\mathrm{K}=0.904$ ) (Table 1). In 2006 the total area was 2,562 ha (21.1\%). The health condition was constant in the lower classes from 1986 to 1995 but we noticed a slight increase in classes 3 and 4 in the same period. In 2006, class 5 (decrepit) was much higher, but also class 2 was higher than in the previous period

(table 2; Fig. 1). These frequencies were reflected by a general increase in the mean value of chestnut disease incidence during the period of analysis. Differences in disease incidence mean and variance between 1986 and 1995 were not significant $(\mathrm{P}=0.6465$; $\mathrm{P}=0.4838$ ). From 1995 to 2006, however, we observed a significant increment in the global level damage $\left(\mathrm{P}<0.0001^{* * *} ; \mathrm{P}=0.0016^{* *}\right)$. The coefficients of variation calculated for 1986, 1995 and 2006 (32.7\%, 30.2\%, and 32.7\%, respectively) showed a moderate variability (12 to 60\%) pattern of the categorical evaluation (Warrick and Nielsen, 1980). 
Plantations have exceeded mortality in the study area (Table 3). The chestnut area increased $147 \pm 6.1 \%$ in the study period but higher spread of chestnut decline rate was observed in 2006, particularly in areas where soil tillage is more frequent. Those practices have been considered as the main causes of transport of soil infested with chlamydospores and other inocula of Phytophthora species (Abreu, 1992; Martins et al., 1999). The more severe chestnut decline observed in 2006 is probably a consequence of chestnut blight incidence. The higher mechanization and also the very dry and hot summers between 1995 and 2006 may have caused the observed higher tree mortality. Probably as a consequence of these factors, in 2006 the disease incidence level increased. In these areas, the clustering effect is more evident in the damage level prediction maps of 2006 but it was already present in 1995 and 1986 (Fig. 2). The spatial distribution of decline (darker tones in Fig. 2) indicated that there is a tendency for higher levels of disease incidence in the same places (e.g., North of Carrazeda de Montenegro, Padrela, and Tazem).

Variograms indicated a moderate dependence degree of 1986, 1995 and 2006 health condition data (Table 4; Fig. 1). The coefficients calculated by cross-validation indicated good prediction: prediction errors near zero, RMSSE and absolute difference between ME and RMSE near one, and low values of MAE, MPE and MAPE. The prediction maps obtained from ordinary kriging (

Fig. 2) were, therefore, a valuable estimation of spatial distribution of disease incidence in the region.

\section{Literature Cited}

Abreu, C.G. 1992. Chestnut Ink Disease: management practices and resistance. p.153157. In: R.D. Wallace and L.G. Spinella (eds.), World Chestnut Industry Conference. Morgantown, West Virginia.

Ambrosini, I., Gherardi, L., Viti, M., Maresi, G. and Turchetti, T. 1997. Monitoring diseases of chestnut stands by small format aerial photography. Geocarto Int. 12:4146.

Bissegger, M. and Heiniger, U. 1994. Aerial photographs reveal chestnut - blight foci. European Journal of Forest Pathology 24:419-423.

Cambardella, C.A., Moorman, T.B., Novak, J.M., Parkin, T.B., Karlen, D.L., Turco, R.F. and Konopka, A.E. 1994. Field-scale variability of soil properties in Central Iowa Soil. Soil Science Society of America Journal 58(5):1501-1511.

Cohen, J. 1960. A coefficient of agreement for nominal scales, Educational and Psychological Measurement 20:37-46.

Congalton, R. 1991. A Review of Assessing the Accuracy of Classification Remotely Sensed Data. Remote Sensing of Environment, USA 37:35-36.

Diggle, P.J. 2000. Overview of statistical methods for disease mapping and its relationship to cluster detection. Lancaster Univesity, 18p.

Fonseca, T.F., Abreu, C.G. and Parresol, B.R. 2004. Soil compaction and Chestnut Ink Disease. Forest Pathology 34:273-283.

Isaaks, E.H. and Srivastava, R.M. 1989. An Introduction to Applied Geostatistics. Oxford University Press. New York. 572p.

Krige, D.G. 1951. A statistical approach to some basic mine valuation problems on the Witwatersrand. J. of the Chem., Metal. and Mining Soc. of South Africa 52(6):119139.

Martins, L., Castro, J., Marques, C. and Abreu, C. 2009. Assessment of the spread of chestnut ink disease from 1995 to 2005 using aerial photography and geostatistical methods. Acta Hort. 844:349-354

Martins, L.M., Castro, J.P., Macedo, F.W., Marques C.P. and Abreu. C.G. 2007. Assessment of the spread of Chestnut Ink Disease using remote sensing and geostatistical methods. European Journal of Plant Pathology 119(2):159-164.

Martins, L.M., Lufinha, M.I., Marques, C.P. and Abreu, C.G. 2001. Small format aerial photography to assess Chestnut Ink Disease. Forest Snow and Landscape Research 73:357-360. 
Martins, L.M., Macedo, F.W., Marques, C.P. and Abreu, C.G. 2005. Assessment of Chestnut Ink Disease spread by geostatistical methods. Acta Hort. 693:621-625.

Martins, L.M., Oliveira, M.T. and Abreu, C.G. 1999. Soils and climatic characteristic of chestnut stands that differ on the presence of the Ink Disease. Acta Hort. 494:447-449.

Portela, E.O., Reboredo, M.O. and Louzada, J. 2003. Assessment and description of magnesium deficiencies in chestnut groves. J. Plant Nutr. 26:503-523.

Portela, E., Aranha, J., Martins, A. and Pires, A.L. 1999. Soil factors, farmer's practices and Chestnut Ink Disease: some interactions. Acta Hort. 494:433-441.

Soares, A. 2000. Geoestatística para as ciências da terra e do ambiente. IST Press. Lisboa.

Vannini, A., Vettraino, A.M., Fabi, A., Montaghi, A., Valentini, R. and Belli, C. 2005. Monitoring ink disease of chestnut with the airborne multispectral system A.S.P.I.S. Acta Hort. 693:529-533.

Warrick, A.W. and Nielsen, D.R. 1980. Spatial variability of soil physical properties in the field. p.319-344. In: D. Hillel (ed.), Applications of Soil Physics. Academic Press, New York.

Zentmyer, G. 1980. Phytophthora cinnamomi and the diseases it causes. Monograph $\mathrm{n}^{\circ} 10$. The American Phytopathological Society, St. Paul, MN, 96p.

\section{Tables}

Table 1. Chestnut area in the study area by parish.

\begin{tabular}{|c|c|c|c|c|c|c|c|}
\hline \multirow{3}{*}{ Parish } & \multirow{3}{*}{$\begin{array}{l}\text { Total } \\
\text { area } \\
\text { (ha) }\end{array}$} & \multicolumn{6}{|c|}{ Sweet chestnut area } \\
\hline & & \multicolumn{2}{|c|}{1986} & \multicolumn{2}{|c|}{1995} & \multicolumn{2}{|c|}{2006} \\
\hline & & (ha) & $(\%)$ & (ha) & $(\%)$ & (ha) & $(\%)$ \\
\hline Car. Montenegro & 2865.0 & 547.0 & 18 & 701.7 & 24 & 804.7 & 28 \\
\hline S. João Corveira & 1836.1 & 463.6 & 24 & 594.7 & 32 & 682.0 & 37 \\
\hline Padrela e Tazem & 2841.5 & 360.9 & 12 & 462.9 & 16 & 530.8 & 19 \\
\hline St Ribeira Alhariz & 1457.0 & 210.6 & 14 & 270.1 & 19 & 309.7 & 21 \\
\hline Serapicos & 1162.9 & 106.5 & 9 & 136.6 & 12 & 156.6 & 13 \\
\hline Curros & 2000.0 & 52.9 & 3 & 67.9 & 3 & 77.9 & 4 \\
\hline TOTAL & 12162.5 & 1741.5 & 13.8 & 2233.9 & 18.4 & 2561.7 & 21.1 \\
\hline
\end{tabular}


Table 2. Descriptive statistics for damage at the plot level evaluated based on a categorical scale (1 - healthy; 5 - decrepit) for 1986, 1995 and 2006.

\begin{tabular}{lccc}
\hline & 1986 & 1995 & 2006 \\
\hline Number of plots & 124 & 139 & 148 \\
25\% Percentile & 2.00 & 2.00 & 2.20 \\
Median & 2.19 & 2.38 & 2.64 \\
75\% Percentile & 2.85 & 2.88 & 3.41 \\
Mean & 2.33 & 2.37 & 2.87 \\
Std. Deviation & 0.762 & 0.717 & 0.936 \\
Std. Error & 0.0684 & 0.0608 & 0.0770 \\
D’Agostino \& Pearson normality test (P value) & $0.4251 \mathrm{~ns}$ & $0.5924 \mathrm{~ns}$ & $0.0156^{*}$ \\
Passed normality test (alpha=0.05)? & Yes & Yes & No \\
Coefficient of variation & $32.68 \%$ & $30.20 \%$ & $32.66 \%$ \\
Skewness & 0.280 & -0.104 & 0.598 \\
Kurtosis & -0.109 & -0.348 & -0.133 \\
\hline
\end{tabular}

Table 3. Chestnut area dynamics since 1986 to 2006.

\begin{tabular}{|c|c|c|c|c|c|c|c|}
\hline \multirow{2}{*}{ \pm Sampling Error (\%) } & \multirow{2}{*}{1986} & \multicolumn{2}{|c|}{ 1986-1995 } & \multirow{2}{*}{1995} & \multicolumn{2}{|c|}{$1995-200$} & \multirow{2}{*}{2006} \\
\hline & & Plantations & Mortality & & Plantations & Mortality & \\
\hline TOTAL (ha) & 1741.5 & & & 2233.9 & & & 2561.7 \\
\hline Area dynamics (\%) & & & & 28.3 & & & 14.7 \\
\hline Area dynamics (ha) & & 1680.5 & -588.3 & 492.4 & 1171.3 & -472.3 & 327.8 \\
\hline Sampling Error (\%) & 10.1 & 14.3 & 23.5 & 6.9 & 20.2 & 30.3 & 6.1 \\
\hline
\end{tabular}

Table 4. Variogram parameters and estimation coefficients obtained after cross-validation of the prediction (1986, 1995 and 2006).

\begin{tabular}{lccclccc}
\hline \multicolumn{2}{l}{ Variogram parameters } & \multicolumn{7}{c}{ Estimation coefficients } \\
\hline Lag size & 1986 & 1995 & 2006 & & 1986 & 1995 & 2006 \\
Num lags & 425 & 425 & 425 & ME & 0.002 & -0.002 & -0.001 \\
Partial sill & 12 & 12 & 12 & RMSE & 0.757 & 0.984 & 1.048 \\
Nugget & 0.455 & 0.760 & 0.871 & ASE & 0.754 & 0.840 & 0.976 \\
Sill & 0.490 & 0.594 & 0.813 & MSE & 0.001 & -0.002 & -0.002 \\
DD & 0.945 & 1.354 & 1.684 & RMSSE & 1.005 & 1.172 & 1.073 \\
& $52 \%$ & $44 \%$ & $48 \%$ & MPE & $-11 \%$ & $-17 \%$ & $-13 \%$ \\
Model & Moderate & Moderate & Moderate & MAPE & $27 \%$ & $36 \%$ & $29 \%$ \\
Dependence Degree (DD), Mean Error (ME), Root-Mean-Square (RMSE), Average Standard Error (ASE), \\
Mean Standardized Error (MSE), Root-Mean-Square Standardized Error (RMSSE), Mean Percentage Error \\
(MPE), Mean Absolute Percentage Error (MAPE)
\end{tabular}




\section{Figures}
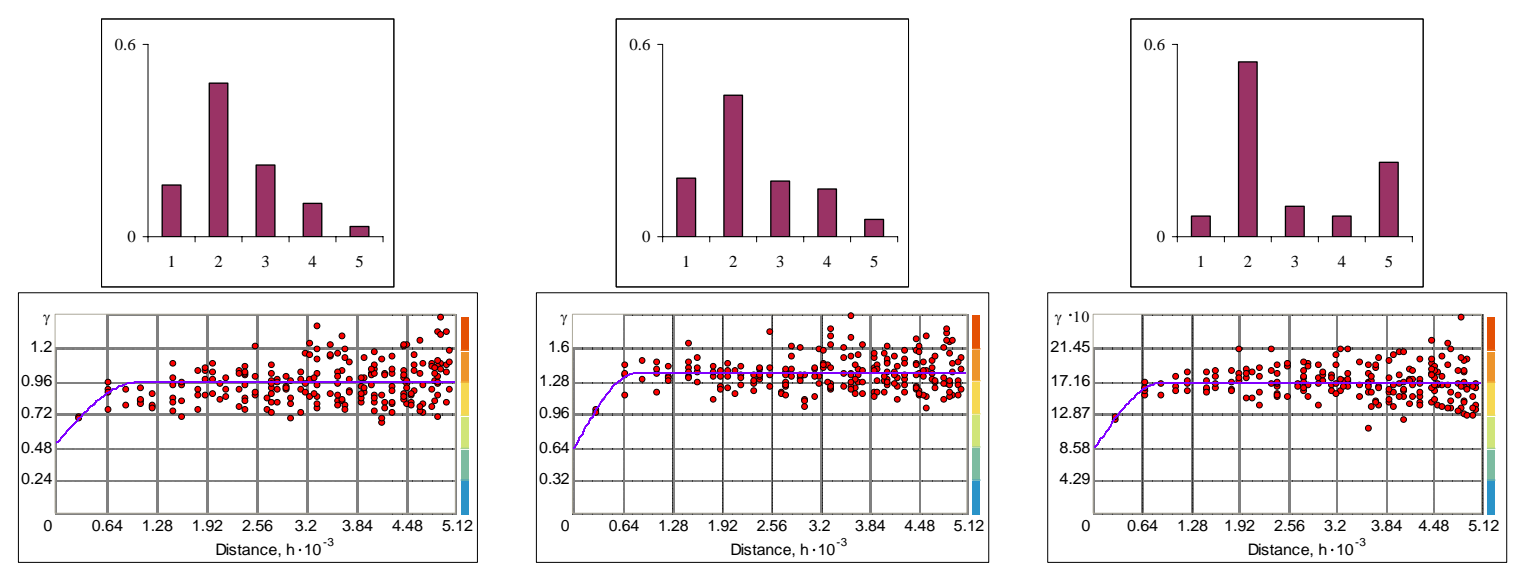

Fig. 1. Histograms of relative frequency of damage evaluated based on a categorical scale (1 - healthy; 5 - decrepit). Top: Left: 1986; center: 1995; right: 2006. Semivariograms for health condition data in the Padrela Mountain. Bottom: Left: 1986; center: 1995; right: 2006.
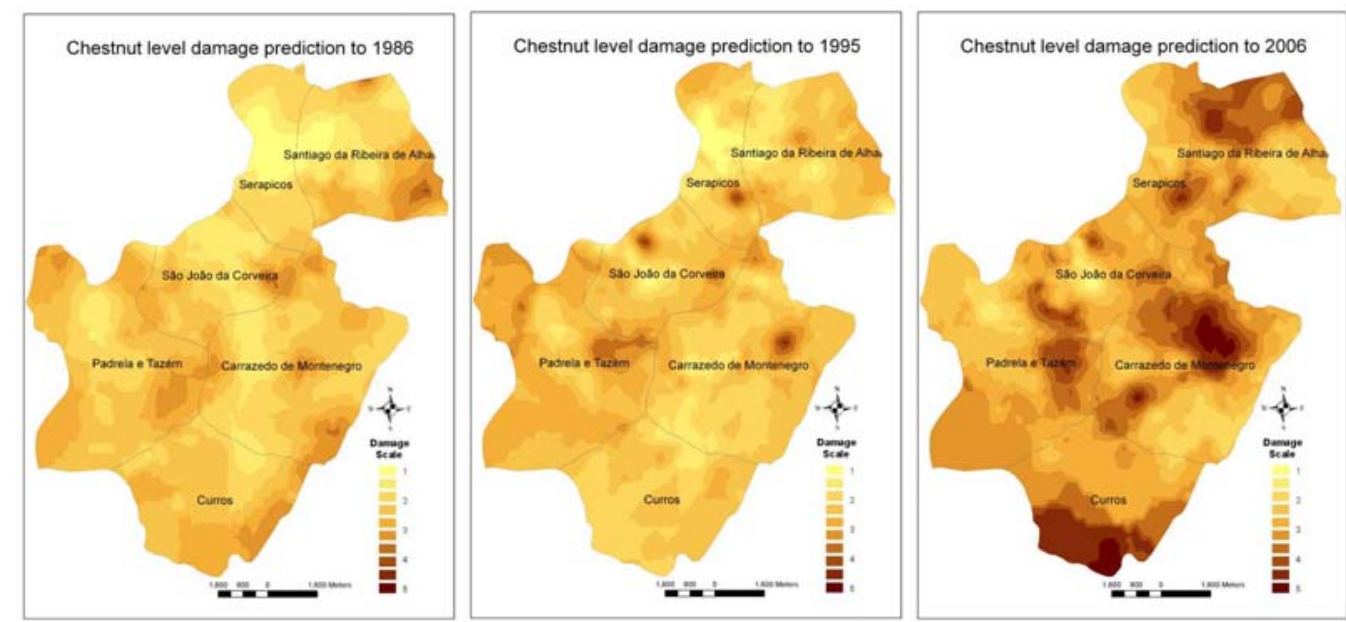

Fig. 2. Ordinary Kriging Prediction maps for 1986, 1995 and 2006. 